\title{
Recurrent Atrial Flutter in Apical Hypertrophic Cardiomyopathy
}

\author{
Isidoros P. Gavaliatsis, M.D., Nikos M. Kouvousis, M.D., \\ Loukianos S. Rallidis, M.D., John M. Pirros, M.D., \\ Chrisoula T. Dionisopoulou, M.D., Dimitrios T. Kremastinos, M.D., \\ and George K. Tsitouris, M.D.
}

\begin{abstract}
Summary
Palpitations are a symptom often reported by patients with apical hypertrophic cardiomyopathy (HCM), yet the arrhythmias associated with this type of HCM have not been studied adequately. Herein, a case of persistently recurrent atrial flutter in a 63-year-old Greek man with apical HCM is presented. Synchronized direct-current shocks were used twice during his hospitalization in order to convert atrial flutter to sinus rhythm. No definite precipitating factor for the induction of atrial flutter was identified.
\end{abstract}

Key Words :

Atrial flutter Hypertrophic cardiomyopathy Arrhythmias

GINCE Yamaguchi et $a^{11}$ first described apical hypertrophic cardiomyoDathy (HCM) in Japanese patients, reports of this unique form of nonobstructive HCM in patients outside of Japan have appeared in the literature. ${ }^{2), 31}$ However, in contrast to other forms of HCM, there have been very few reports of the arrhythmias associated with this particular variant of HCM.4) We describe the first reported case of recurrent atrial flutter in a patient with apical HCM.

\section{CAse Report}

A 63-year-old Greek man was admitted to the hospital because of palpitations which he had been feeling for 15 days. The electrocardiogram (ECG) showed atrial flutter with $2: 1,3: 1$, and $4: 1$ atrioventricular (AV) conduction (Fig. 1A). Episodes of atrial flutter, of 2 hours to 6 days duration, had

From the Second Department of Cardiology, Evangelismos Hospital, Athens and the Department of Cardiology, Athens General Hospital, Athens, Greece.

Address for correspondence: Isidoros P. Gavaliatsis, M.D., 17 Pythagora Street, Holargos, 155 62 Athens, Greece.

Received for publication November 20, 1991.

Accepted March 3, 1992. 
been reported during the previous 6 years. Their mean rate was 1 episode per month in spite of the antiarrhythmic drugs, of all the known classes, that the patient had received. His last medications were digoxin, verapamil, and
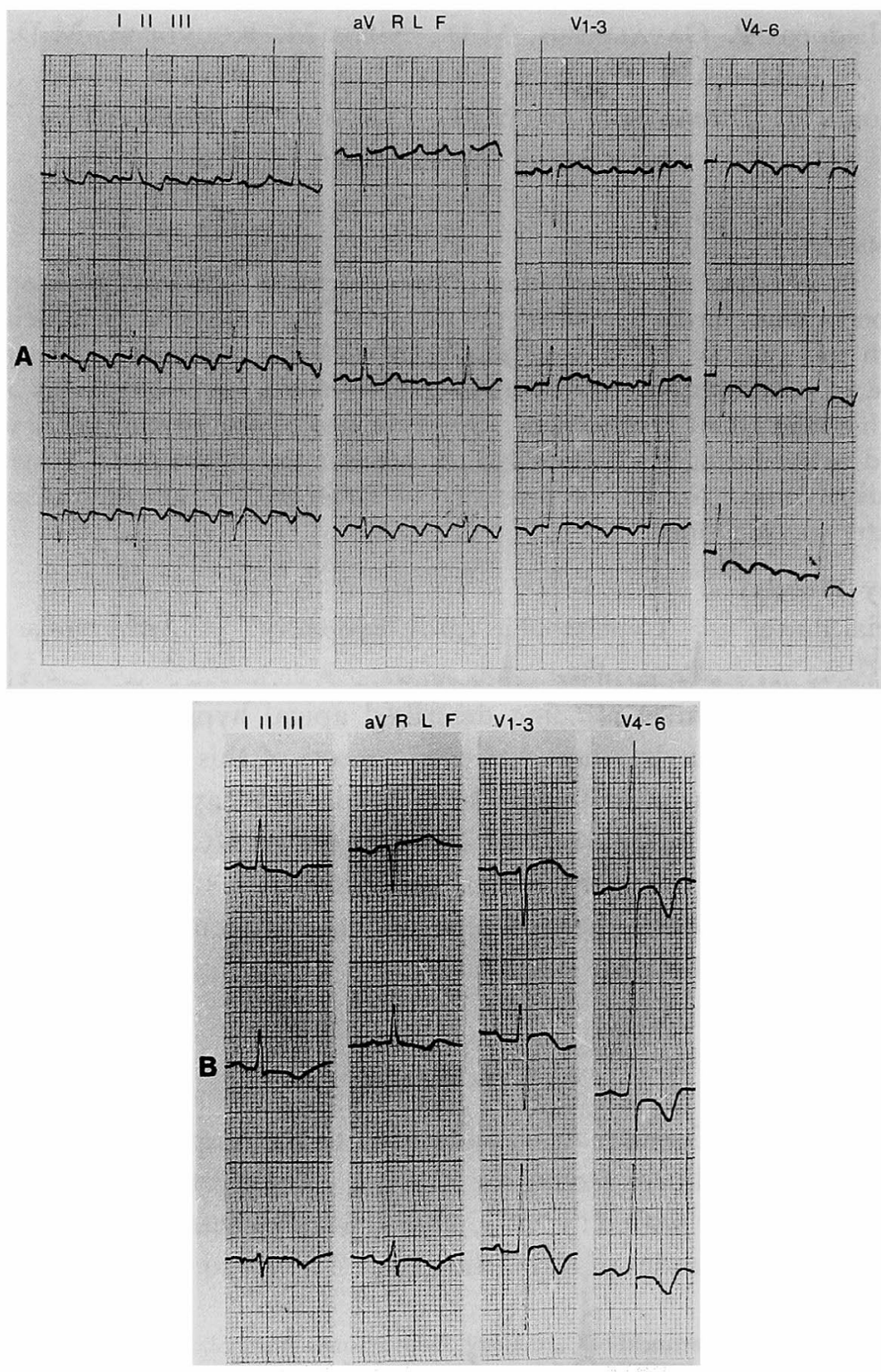

Fig. 1. A: ECG showing type I atrial flutter (atrial rate is about 300 beats/min). B: ECG with sinus rhythm and inverted $T$ waves predominantly in leads $V_{4-6}$. Maximum depth of the $T$ waves in $V_{4}$ is $6 \mathrm{~mm}$. $R$ wave in lead $V_{5}$ is $23 \mathrm{~mm}$ and the $S V_{1}+R V_{5}$ value is $33 \mathrm{~mm}$. 
propafenone. Symptoms other than palpitations were not reported. There was no history of arterial hypertension. On examination, blood pressure was $115 / 80 \mathrm{mmHg}$. Cardiac auscultation revealed variable intensity of the first heart sound and a $2 / 6$ systolic ejection murmur. Chest $\mathrm{x}$ rays, and blood chemistry, except for cholesterol $(280 \mathrm{mg} \%)$, as well as thyroid function tests were within normal limits. The 24-hour ECG recording showed atrial flutter with $1: 1$ to $5: 1 \mathrm{AV}$ conduction. Atrial flutter was converted to sinus rhythm using a synchronized direct-current (DC) shock of 50 joules. The ECG showed moderately negative $T$ waves and marginally high QRS voltage in the precordial leads (Fig. 1B). Afterwards, the patient was given amiodarone as an intravenous loading dose for 4 days and then continued orally. Transthoracic and transesophageal two-dimensional echocardiography demonstrated apical hypertrophy of the left ventricle (Fig. 2). Left atrial dimension was $4.17 \mathrm{~cm}$. Other echocardiographic and Doppler findings were normal. Cardiac catheterization and angiography revealed normal coronary arteries, normal intracardiac pressures (left ventricular enddiastolic pressure was $14 \mathrm{mmHg}$ ) and a left ventriculogram with a typical "spade-like" configuration at end-diastole and vigorous systolic contraction (Fig. 3). Ejection fraction was calculated to be $60 \%$. Ten days after cardioversion, atrial flutter recurred. Rapid atrial pacing was unsuccessful and a second 50-joule DC shock, under a temporary pacemaker stand-by, restored sinus rhythm. The patient was discharged, receiving amiodarone and oral anticoagulants. Oral anticoagulation was administered throughout the patient's hospitalization.
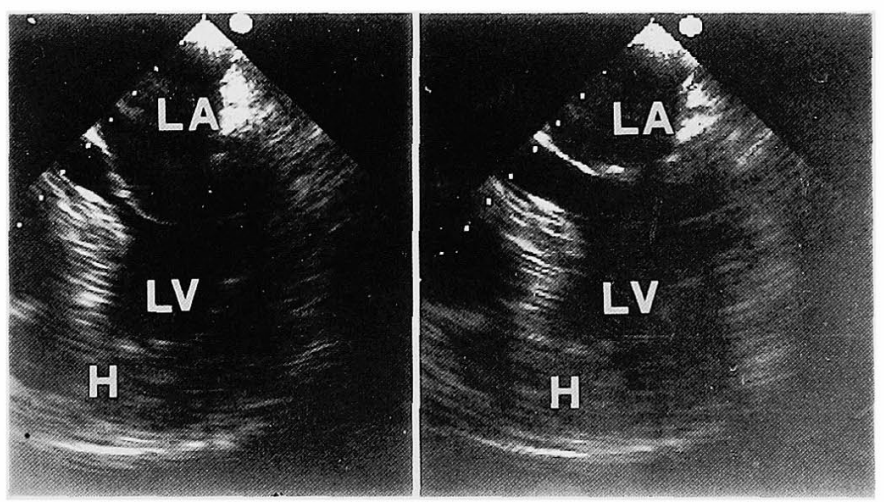

Fig. 2. Diastolic (left) and systolic (right) transesophageal two-dimensional echocardiographic views of the left ventricle (LV) and left atrium (LA). Apical hypertrophy $(\mathrm{H})$ is depicted. 


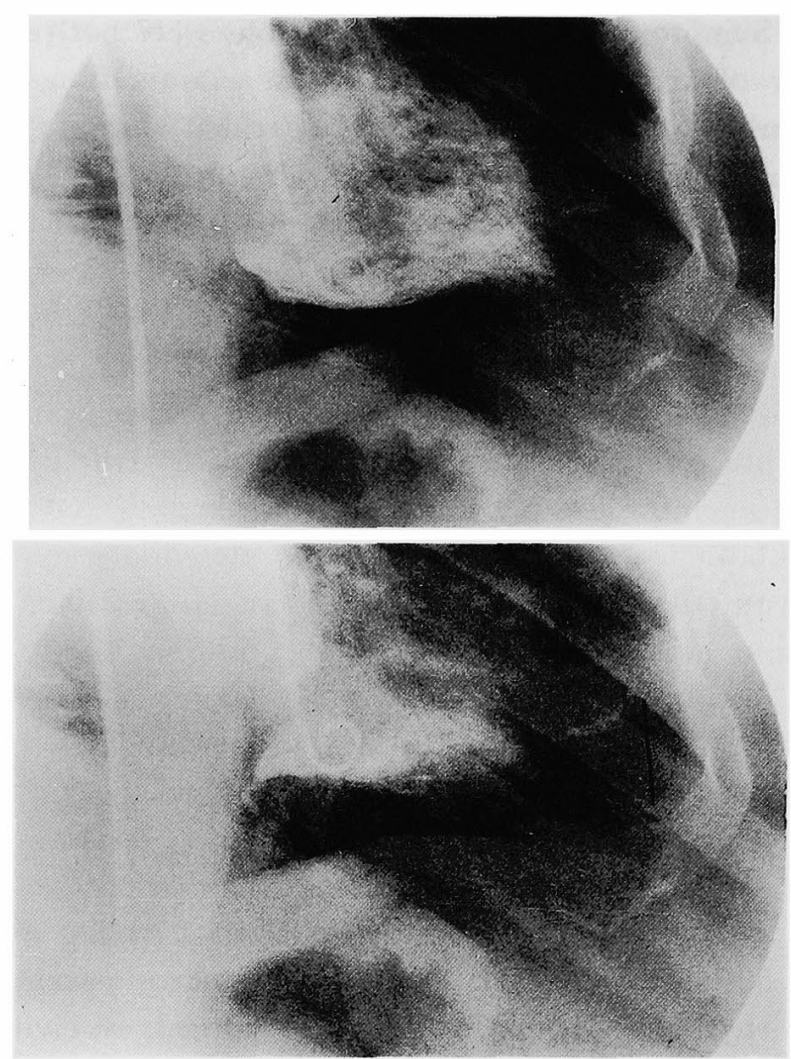

Fig. 3. End-diastolic (top) and end-systolic (bottom) left ventriculogram in right anterior oblique projection. A "spade-like" end-diastolic appearance and a vigorous systolic contraction are apparent.

\section{Discussion}

Although palpitations are a symptom often reported by patients with apical HCM, ${ }^{1-3}$ ) the arrhythmias associated with this type of HCM have not been studied adequately. Hayano et al $^{4}$ described a case of LownGanong-Levine syndrome and supraventricular tachycardia in a patient with apical HCM. To our knowledge, no report of atrial flutter in association with apical HCM has been previously published. Supraventricular arrhythmias have been reported in conjunction with HCM; yet atrial flutter is not a common finding even in these patients. ${ }^{5), 6)}$ Atrial flutter itself is relatively uncommon. Furthermore, no definite causal relationship between arrhythmias and HCM has been identified.7) Similarly, no particular precipitating factor for the induction of atrial flutter was detected in our case, except for the potential contribution of the mild left atrial enlargement. 
Persistently recurring atrial flutter, as in our case, is usually associated with underlying heart disease such as cardiomyopathy and coincidental occurrence (and reoccurrence?) of the arrhythmia is not very likely, although it is difficult to exclude it. ${ }^{8)}$ Mild left atrial enlargement could be considered a potential contributor to the induction of the arrhythmia but not a substrate for it since the atrial flutter reentrant circuit is located predominantly in the right atrium.9,10) However, the common form of atrial flutter, i.e. with negative atrial waves in the inferior leads and positive waves in $a V_{R}$ and $\mathrm{a} V_{\mathrm{L}}$, and with continuous undulation of the baseline, as was the type I atrial flutter in this case, supposedly originates in the low part of one of the atria. ${ }^{111,12)}$ Bcsides, the right atrium was not enlarged in this case. Finally, as for the particular type of apical HCM in our Greek patient, "non-Japanese type" ECG features coexisted with "Japanese type" angiographic ones, implying that such subclassification of apical HCM is not strictly applicable. ${ }^{3 \prime}$

\section{REFERENCES}

1. Yamaguchi H, Ishimura T, Nishiyama S, Nagasaki F, Nakanishi S, Takatsu F, Nishijo T, Umeda T, Machii K: Hypertrophic nonobstructive cardiomyopathy with giant negative $\mathrm{T}$ waves (apical hypertrophy): Ventriculographic and echocardiographic features in 30 patients. Am J Cardiol 44: 401, 1979

2. Vacek JL, Davis WR, Bellinger RL, McKiernan TL: Apical hypertrophic cardiomyopathy in American patients. Am Heart J 108: 1501, 1984

3. Keren G, Belhassen B, Sherez J, Miller H, Megidish R, Berenfeld D, Laniado S: Apical hypertrophic cardiomyopathy: evaluation by noninvasive and invasive techniques in 23 patients. Circulation 71: 45, 1985

4. Hayano $M$, Imamura $Y$, Tsuruta $M$, Inoue J, Nakashima $H$, Fukuyama $K$, Eguchi $Y$, Tsuji S, Matsuo S, Yano K: Supraventricular tachycardia in a patient with Lown-GanongLevine syndrome associated with apical hypertrophic cardiomyopathy. Jpn Heart J 29: 249, 1988

5. McKenna WJ, England D, Doi YL, Deanfield JE, Oakley C, Goodwin JF: Arrhythmia in hypertrophic cardiomyopathy. Br Heart J 46: 168, 1981

6. Frank MJ, Watkins LO, Prisant LM, Stefadouros MA, Abdulla AM: Potentially lethal arrhythmias and their management in hypertrophic cardiomyopathy. Am J Cardiol 53: 1608,1984

7. McKenna WJ, Chetty S, Oakley CM, Goodwin JF: Arrhythmia in hypertrophic cardiomyopathy: excrcise and 48 hour ambulatory clectrocardiographic assessment with and without beta adrenergic blocking therapy. Am J Cardiol 45: 1, 1980

8. Zipes DP: Specific arrhythmias: diagnosis and treatment. in Heart Disease, ed by Braunwald E, WB Saunders, Philadelphia, p 672, 1988

9. Disertori M, Inama G, Vergara G, Cuarnerio M, Del Favero A, Furlanerro F : Evidence of a reentry circuit in the common type of atrial flutter in man. Girculation 67:434, 1983

10. Della Bella P, Marenzi G, Tondo G, Cardinale D, Giraldi F, Lauri G, Guazzi M: Usefulness of excitable gap and pattern of resetting in atrial flutter for determining reentry circuit location. Am J Cardiol 68: 492, 1991

11. Marriott HJL: Practical Electrocardiography, Williams \& Wilkins, Baltimore, p 186, 1988 
12. Wells JL, MacLean WAH, James TN, Waldo AL: Characterization of atrial flutter. Studies in man after open heart surgery using fixed atrial electrodes. Circulation 60: 665, 1979 